\title{
Nematoides fitoparasitas em seringais do Estado de São Paulo
}

\author{
Silvia Renata Siciliano Wilcken ${ }^{1}$, Adriana Aparecida Gabia ${ }^{1}$, Paulo Fernando de Brito ${ }^{2}$, Edson Luiz Furtado ${ }^{1}$
}

${ }^{1}$ Departamento de Proteção Vegetal, Faculdade de Ciências Agronômicas, Campus de Botucatu, SP, CEP: 18.610-307. ${ }^{2}$ Escritório de Defesa Agropecuária/Coordenadoria de Defesa Agropecuária, Secretaria de Agricultura e Abastecimento, Barretos, SP.

Autor para correspondência: Silvia Renata Siciliano Wilcken (srenata@fca.unesp.br).

Data de chegada: 15/08/2014. Aceito para publicação em: 19/12/2014.

$10.1590 / 0100-5405 / 2025$

\section{RESUMO}

Wilcken, S.R.S.; Gabia, A.A.; Brito, P.F.; Furtado. E.L. Effect of temperature, wetness duration and cultivar on the development of anthracnose in guava fruits. Summa Phytopathologica, v.41, n.1, p.54-57, 2015.

A seringueira, Hevea brasiliensis, é nativa da região Amazônica e a espécie mais importante do gênero. O estado de São Paulo é o maior produtor nacional com uma área plantada de cerca de 90.000 hectares. Por muito tempo as mudas de seringueira foram produzidas diretamente no solo ou em sacolas plásticas com substrato a base de terra de barranco sem tratamento, o que propiciou a disseminação de pragas e patógenos do sistema radicular. O objetivo do presente estudo foi determinar a incidência de fitonematoides em seringais do estado de São Paulo. Foi realizada a amostragem de 75 seringais distribuídos em 64 municípios do Estado, no período de 2011 e 2012. As amostragens foram realizadas em solo e raiz de seringais georreferenciados, com mais de oito anos de produção, formados com diferentes clones, com predominância do clone
RRIM 600. As amostras foram acondicionadas em sacos plásticos, etiquetados e encaminhadas ao Laboratório de Nematologia da FCA/UNESP, Botucatu, SP, onde foram processadas para extração dos nematoides. Pratylenchus brachyurus foi encontrado em $66 \%$ dos municípios amostrados. Nematoides do gênero Meloidogyne, tiveram ocorrência em 49,3\% dos municípios. Os nematoides dos gêneros Rotylenchulus e Paratrichodorus foram detectados em 5,3\% e 2,6\% das amostras, respectivamente. Representantes da família Criconematidae foram encontrados em 1,3\% dos seringais amostrados. De acordo com os resultados obtidos, observa-se que P. brachyurus e o gênero Meloidogyne já se encontram distribuidos na maioria dos cultivos de seringueira do estado, porém, em nível populacional relativamente baixo.

Palavras-chave adicionais: Hevea brasiliensis, estudo, nematoides.

\section{ABSTRACT}

Wilcken, S.R.S.; Gabia, A.A.; Brito, P.F.; Furtado. E.L. Phytoparasite nematodes in rubber plantations of São Paulo State. Summa Phytopathologica, v.41, n.1, p.54-57, 2015.

The rubber tree, Hevea brasiliensis, is native to the Amazon region and is the most important species of its genus. The state of São Paulo is the largest national producer, showing a planted area of approximately 90,000 hectares. For a long time, rubber tree seedlings were produced directly in the soil or in plastic bags containing ravine soil-based substrate without treatment, which led to the spread of pests and pathogens of the root system. The aim of this study was to determine the incidence of nematodes in rubber plantations of São Paulo State. Sampling of 75 rubber plantations spread over 64 cities in the state was done in the period between 2011 and 2012. The samples were taken from the soil and the root of georeferenced rubber trees with more than eight years of production and formed with different clones, predominating clone RRIM 600. The samples were packed in plastic, labeled bags and sent to the Laboratory of Nematology, FCA/ UNESP, Botucatu, SP, where they were processed for extraction of nematodes. Pratylenchus brachyurus was found in $66 \%$ of the sampled cities. Nematodes of the genus Meloidogyne occurred in $49.3 \%$ of the cities. Nematodes of the genus Rotylenchulus and Paratrichodorus were detected in 5.3\% and $2.6 \%$ of the samples, respectively. Representatives of the Criconematidae family were found in $1.3 \%$ of the sampled rubber plantations. According to the results, $P$. brachyurus and the genus Meloidogyne are already distributed over most rubber tree plantations in the state, but at relatively low population level.

Additional keywords: Hevea brasiliensis, study, nematodes

A seringueira, Hevea brasiliensis Müell. Arg., nativa da região Amazônica é considerada a espécie mais importante do gênero, por apresentar alta diversidade genética e alto potencial de produção de látex para a produção de borracha natural (4). Após a fase de produção da borracha por extrativismo, a seringueira passou a ser cultivada em grandes monocultivos. Os países do sudeste asiático produzem mais de $90 \%$ do total mundial da borracha natural, sendo os maiores produtores Tailândia, Indonésia, Malásia, China e Vietnã. No Brasil, a maioria dos cultivos se encontram nas regiões Sudeste, Centro-oeste, na Bahia e no Oeste do Paraná (1), sendo São Paulo o principal produtor de borracha natural do Brasil, com a heveicultura concentrada nas regiões de clima tropical ao norte do Estado, devido às exigências climáticas da cultura (5).

O estado de São Paulo possui uma área plantada de cerca de 90.000 hectares. Com mais de 14 milhões de pés em produção e mais de 4,5 milhões de pés novos, com previsão de ampliação para 250 mil hectares até 2020 (7).

$\mathrm{O}$ primeiro relato de parasitismo de nematoide em seringueira foi no Congo Belga, em 1921, quando foi observado nematoides das galhas, Meloidogyne sp. (5). Os gêneros Meloidogyne e Pratylenchus são considerados os mais importantes para a cultura. No gênero Pratylenchus a espécie $P$. brachyurus é a mais importante, enquanto no 
gênero Meloidogyne, as espécies $M$. exigua e M. incognita aparecem como as mais daninhas, entretanto $M$. exigua é considerada de maior importância devido principalmente a sua disseminação nos seringais brasileiros (5).

No Brasil, o problema nematológico em seringais ocorreu na região de Rondonópolis, MT, quando se relatou M. exigua $(9,10)$. Essa espécie também foi relatada em áreas de produção de seringueira no município de São José do Rio Claro, também no Estado do Mato Grosso (2).

Fora do Estado de São Paulo e Mato Grosso, M. exigua foi detectado em plantações nos municípios de Prata - MG, Goianésia GO e Nanuque - ES (Laboratório de Nematologia - FCA, dados não publicados).

Dentre as espécies M. exigua, M. incognita e M. javanica, a primeira se destacou nos testes de patogenicidade pela agressividade. No campo, causa o descortiçamento e a morte descendente de ramos, além de possibilitar o ataque de fungos secundários como Lasiodiplodia theobromae.

Por muito tempo, as mudas de seringueira foram produzidas em canteiros diretamente no solo ou em sacos plásticos contendo terra sem tratamento, propiciando a disseminação de pragas e patógenos do sistema radicular (5). O plantio predominante de um único clone RRIM 600 nos seringais paulistas contribui para o agravamento dos problemas fitossanitários (11).

O objetivo do presente trabalho foi determinar a incidência de fitonematoides em seringais do estado de São Paulo, com predominância na região Noroeste, maior produtora do Estado.

\section{MATERIAL E MÉTODOS}

Foi realizada a amostragem em 75 seringais distribuídos em 64 municípios do Estado no período de 2011 e 2012, pelo Escritório/
Coordenadoria de Defesa Agropecuária, da Secretária de Agricultura e Abastecimento - Barretos - SP (Figura 1).

As amostragens foram realizadas em seringais georreferenciados, com mais de oito anos de produção, formado com diferentes clones, com predominância do clone RRIM 600. Os seringais foram subdivididos em lotes com 5.000, 4.000 e 3.000 plantas, de onde foram coletadas 25,20 e 15 sub-amostras de solo e raiz, respectivamente. Cada amostra composta foi constituída por $300 \mathrm{~g}$ de solo e $100 \mathrm{~g}$ de raízes e encaminhadas ao Laboratório de Nematologia da Faculdade de Ciências Agronômicas - UNESP - extraidos de $250 \mathrm{~mL}$ de solo seguindo a metodologia de lavagem, peneiramento e flutuação em centrífuga (6); e de $10 \mathrm{~g}$ de raiz seguindo a metodologia de trituramento, peneiramento e flutuação em centrifuga (3).

Os especimes foram identificados em nível de família quando pertencentes a família Criconematidae, em nível de gênero quando pertencentes aos gêneros Meloidogyne, Rotylenchulus e Paratrichodorus e em nível de espécie para Pratylenchus.

\section{RESULTADOS E DISCUSSÃO}

Dos 75 seringais amostrados $85,3 \%$ apresentaram pelo menos um gênero de nematoide fitoparasita. Nos municípios General Salgado, Macaubal, Palestina, Paraíso, Tabapuã e Tanabi não foram detectados nematoides nos seringais amostrados. P. brachyurus, foi o nematoide mais frequente, presente em $66 \%$ das amostras provenientes de 48 municípios (Tabela 1).

Meloidogyne ocorreu em 49,3\% dos seringais; Rotylenchulus e Paratrichodorus em 5,3\%, e 2,6\%, respectivamente. Representantes da família Criconematidae foram encontrados em 1,3\% dos seringais amostrados (Figura 2).

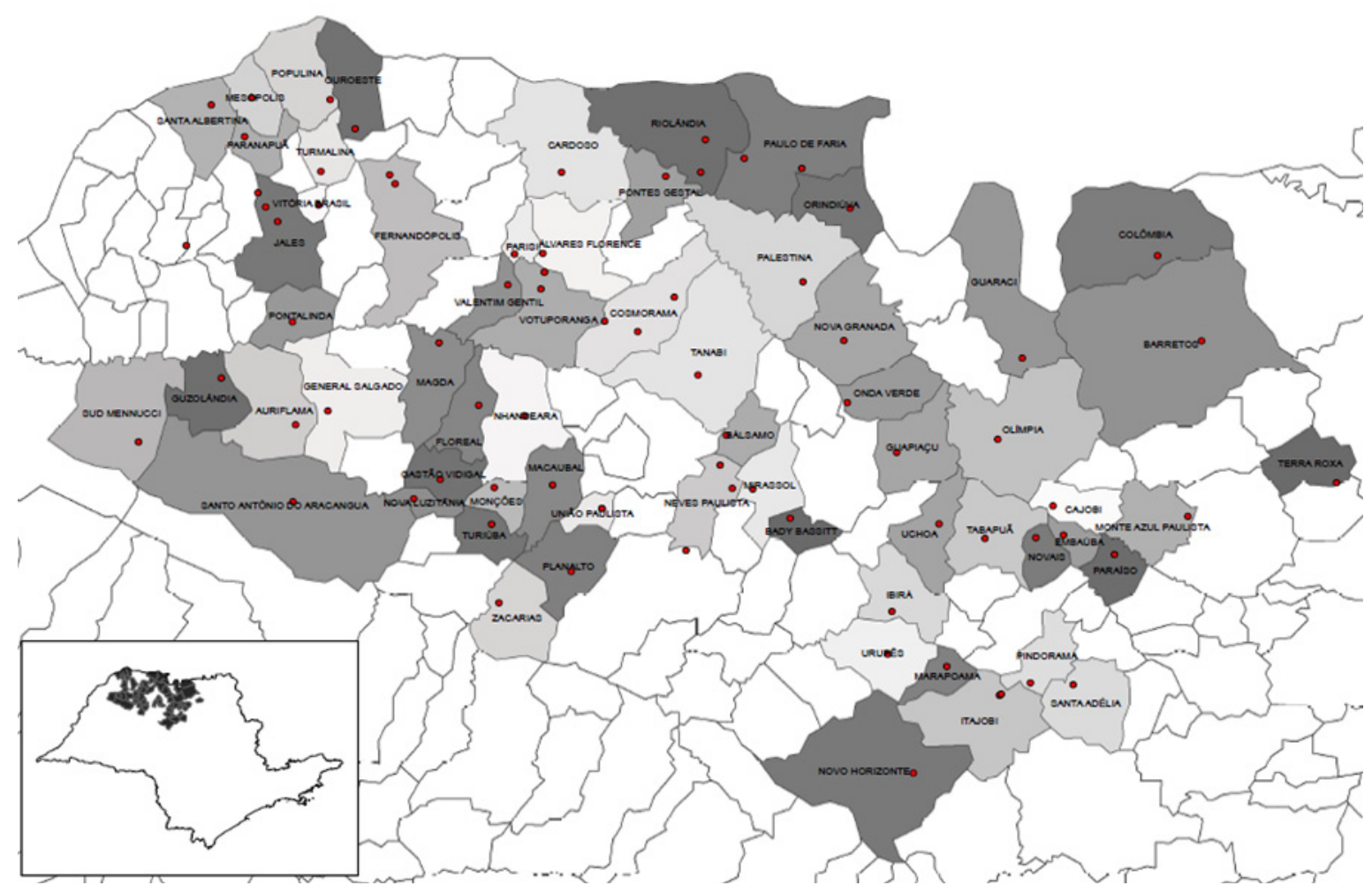

Figura 1. Seringais amostrados no estado de São Paulo, no período de 2011 e 2012. 
Tabela 1. Nematoides encontrados em amostras de solo e raiz, provenientes de seringais paulista, coletadas no periodo de 2011 e 2012.

\begin{tabular}{|c|c|c|c|c|c|}
\hline Municípios & Nematoides & Municípios & Nematoides & Municípios & Nematoides \\
\hline Álvares Florense & $\mathrm{Me} P$ & Magda & $\mathrm{P}$ & Planalto & M \\
\hline Américo de Campos & M & Marapoama & $\mathrm{P}$ & Pontalinda $(2)^{*}$ & $\mathrm{Me} \mathrm{P}$ \\
\hline Auriflama & M & Mesópolis & $\mathrm{M}$ e $\mathrm{P}$ & Pontes Gestal & $\mathrm{M}$ e $\mathrm{P}$ \\
\hline Bady-Bassit & M & Mirassol & M & Populina & $\mathrm{M}$ e $\mathrm{P}$ \\
\hline Bálsamo & $\mathrm{P}$ & Monções & $\mathrm{M}$ e $\mathrm{P}$ & Riolandia $(2)^{*}$ & $\mathrm{M}, \mathrm{P}$ e Pa \\
\hline Barretos & $\mathrm{Pe} \mathrm{C}$ & Mte. Azul Paulista & $\mathrm{P}$ & S. Antonio do Aracanguá & $\mathrm{P}$ \\
\hline Cajobi & $\mathrm{M}, \mathrm{P}$ e R & Neves Paulista (2)* & M & Santa Adélia & $\mathrm{M}$ e $\mathrm{P}$ \\
\hline Cardoso & $\mathrm{MeP}$ & Nhandeara & M & Santa Albertina & $\mathrm{P}$ \\
\hline Colômbia & $\mathrm{P}$ & Nova Granada & $\mathrm{P}$ & Sud Mennucci & $\mathrm{P}$ \\
\hline Cosmorama $(2)^{*}$ & $\mathrm{MeP}$ & Nova Luzitânia & $\mathrm{P}$ & Tabapuã & 0 \\
\hline Embaúba & $\mathrm{P}$ & Novais - SP & $\mathrm{P}$ & Tanabi & 0 \\
\hline Fernandópolis (2)* & $\mathrm{MeP}$ & Novo Horizonte & $\mathrm{Me} P$ & Terra Roxa & $\mathrm{Re} \mathrm{C}$ \\
\hline Floreal & M & Olímpia $(2)^{*}$ & $\mathrm{P}$ & Turiuba & $\mathrm{P}$ \\
\hline Gastão Vidigal & $\mathrm{P}$ & Onda Verde & $\mathrm{P}$ & Turmalina & $\mathrm{P}$ \\
\hline General Salgado & 0 & Orindiuva & M & Uchoa & $\mathrm{M}$ e $\mathrm{P}$ \\
\hline Guapiaçu & $\mathrm{P}$ & Ouro Oeste (2)* & $\mathrm{P}$ & União Paulista & $\mathrm{P}$ \\
\hline Guaraci (4)* & $\mathrm{M}, \mathrm{P}$ e R & Palestina & 0 & Urupês & $\mathrm{P}$ \\
\hline Guzolandia & $\mathrm{P}$ & Paraíso & 0 & Valentim Gentil (2)* & $\mathrm{Pe} \mathrm{Pa}$ \\
\hline Ibirá & $\mathrm{P}$ & Parisi (2)* & $\mathrm{MeP}$ & Vitória Brasil & $\mathrm{P}$ \\
\hline Itajobi $(2)^{*}$ & $\mathrm{M}$ e $\mathrm{P}$ & Paulo de Faria & M & Votuporanga $(3)^{*}$ & $\mathrm{M}, \mathrm{P}$ e R \\
\hline Jales $(3)^{*}$ & $\mathrm{M}$ e $\mathrm{P}$ & Pindorama & $\mathrm{Me} P$ & Zacarias & $\mathrm{P}$ \\
\hline Macaubal & 0 & & & & \\
\hline
\end{tabular}

*Número de propriedades amostradas por município

* $\mathrm{P}=$ Pratylenchus brachyurus, $\mathrm{M}=$ Meloidogyne, $\mathrm{R}=$ Rotylenchulus, $\mathrm{Pa}=$ Paratrichodorus, $\mathrm{C}=$ Criconematideos, $0=$ Não detectado

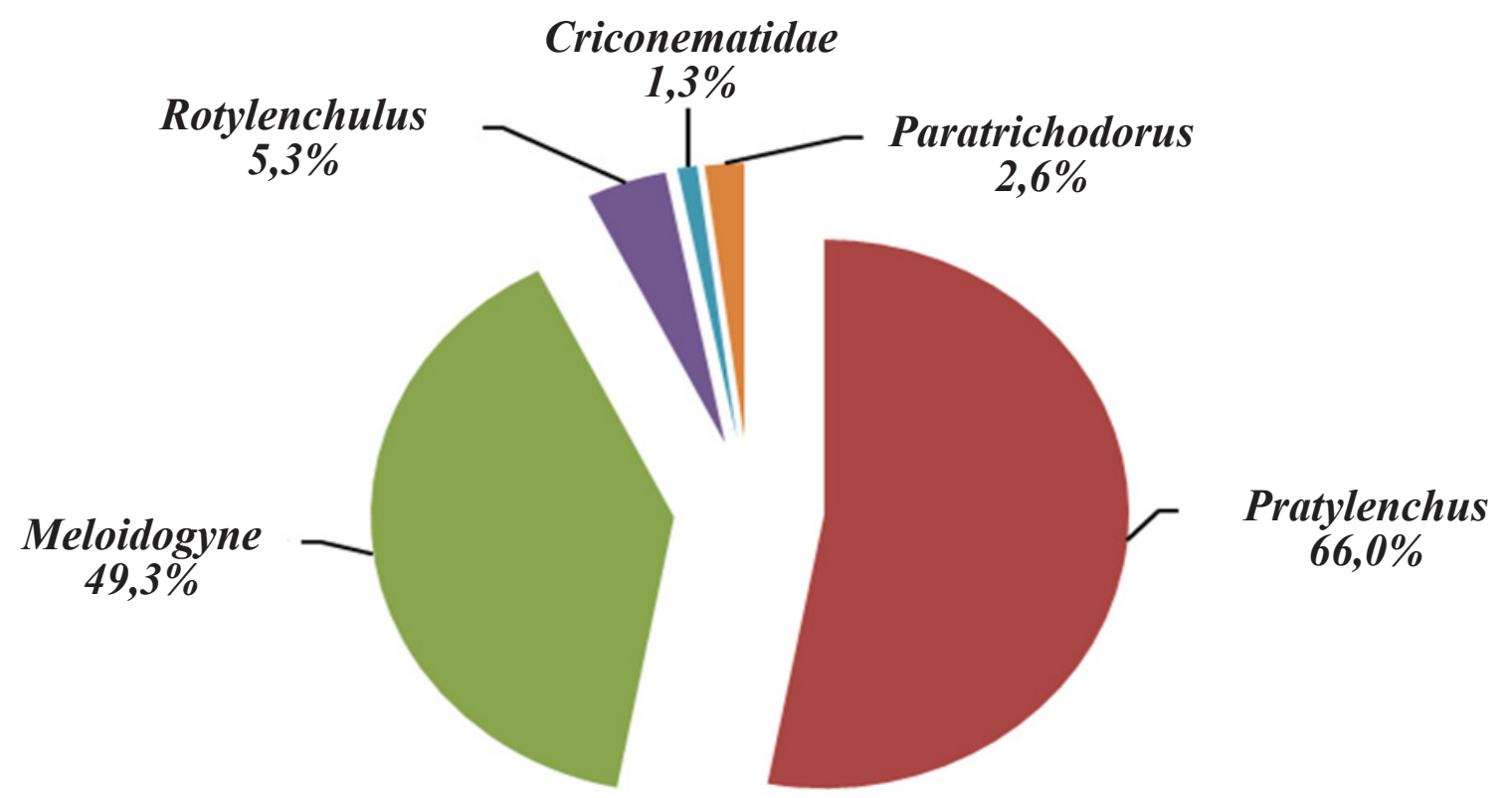

Figura 2. Nematoides encontrados em amostras de solo e raiz, provenientes de seringais paulista, coletadas no periodo de 2011 e 2012. 
Os maiores níveis populacionais de $P$. brachyurus foram 160 nematoides em $250 \mathrm{~mL}$ de solo e 196 nematoides em $10 \mathrm{~g}$ de raiz, encontrados nos municípios de Nova Luzitânia e Itajobi, respectivamente. A população variou de 2 a 100 nematoides em 250 $\mathrm{mL}$ de solo em $91,7 \%$ das amostras e de 100 a 160 nematoides em 250 $\mathrm{mL}$ de solo em $8,3 \%$. Nas amostras de raiz, $81,5 \%$ estavam com níveis populacionais entre 10 a 100 nematoides em $10 \mathrm{~g}$ de raiz e $18,5 \%$, entre 100 a 196 nematoides em $10 \mathrm{~g}$ de raiz.

A maior população do gênero Meloidogyne foi de 320 nematoides em $250 \mathrm{~mL}$ de solo e 256 nematoides em $10 \mathrm{~g}$ de raiz, detectado nos municípios de Novo Horizonte e Pontalinda, respectivamente. Das amostras de solo com Meloidogyne, 87,5\% apresentavam níveis populacionais entre 8 a 100 nematoides em $250 \mathrm{ml}$ de solo e $12,5 \%$ entre 100 a 320 nematoides em $250 \mathrm{~mL}$ de solo. Nas amostras de raiz, $94,7 \%$ apresentavam 16 a 100 nematoides em $10 \mathrm{~g}$ de raiz e 5,3\% entre 100 a 256 nematoides em $10 \mathrm{~g}$ de raiz.

Os demais nematoides apresentaram baixos níveis populacionais, variando de 30 a 60 nematoides em $250 \mathrm{~mL}$ de solo e de 20 a 30 nematoides em $10 \mathrm{~g}$ de raiz, para Rotylenchulus, de 20 a 48 nematoides em $250 \mathrm{~mL}$ de solo para Paratrichodorus e de 0 a 11 nematoides em $250 \mathrm{~mL}$ de solo para criconematídeos.

Os dados demonstram que nos seringais paulistas há instaladas espécies importantes de fitonematoides, embora no presente estudo tenham sido encontradas populações relativamente baixas, as quais ainda não conferem danos às plantas. No entanto, por se tratar de uma cultura perene, tal relato causa preocupação. O gênero Meloidogyne foi o mais frequente em levantamento nematológico realizado em seringais na Índia. Além deste, também foram detectados outros 11 gêneros (12). No Brasil, foi relatada a presença de $M$. exigua em seringais na região de Rondonópolis - MT $(9,10)$ e em seringais no município de São José do Rio Claro (2), também Estado do Mato Grosso.

A conscientização do setor heveícola sobre problemas causados por fitonematoides se faz necessária para que técnicas de manejo sejam adotadas evitando a introdução destes agentes fitopatogênicos em novos seringais. A mudança no sistema de produção de mudas de seringueiras, proposta pela Coordenadoria de Defesa Agropecuária do estado de São Paulo (8) em bancadas suspensas e com substratos sem mistura de terra, deve ser adotada pelo setor, como de reduzir a expansão dos nematoides em seringais.

\section{CONCLUSÃO}

De acordo com os resultados obtidos, verifica-se que P. brachyurus e o gênero Meloidogyne se encontram distribuidos na maioria dos cultivos de seringueira do estado, porém, em nível populacional relativamente baixo. Sendo assim, estudos mais direcionados e detalhados devem ser desenvolvidos, a fim de determinar os reais danos biológicos e econômicos que estes agentes estão causando à cultura.

\section{REFERÊNCIAS BIBLIOGRÁFICAS}

1. AGRIANUAL 2013: Anuário da agricultura brasileira. São Paulo: FNP, 2012.

2. Bernardo, E.R.A.; Santos, J.M.; Silva, R.A.; Cassetari Neto, D.; Santos, S.S.; Delmadi, L.; Rocha, V. F. Levantamento de Meloidogyne exigua na cultura da seringueira em São José do Rio Claro, MT, Brasil. Ciência Rural, Santa Maria, v. 33, n. 1, 3p., 2003.

3. Coolen,W. A.; D'Herde, C. J. A method for the quantitative extraction of nematodes from plant tissue. Ghent, State Agricultural Research Centre, 77p. 1972.

4. Gasparoto, L.; Pereira, J.C.R.; Santos, A. F.; Ferreira, F.A .; Furtado, E.L. Doenças da seringueira no Brasil. 2. ed. Brasilia, DF : Embrapa, 2012. 255 p

5. Gonçalves, E.C.P. A cultura da seringueira para o estado de São Paulo. Campinas: 2010. 163p.

6. Jenkins, W. R. A rapid centrifugal-flootation technique for separating nematodes from soil. Plant Disease Reporter, v. 48, n. 9, p. 692, 1964

7. Martinez, A. A. Borracha: São Paulo é o maior produtor nacional. 2006. Artigo em Hypertexto. Disponível em <http://www.infobibos.com/artigos >. Acesso em: 10 jun. 2012.

8. São Paulo. Coordenadoria de Defesa Agropecuária do Estado de São Paulo. Resolução SAA - 154, DE 22-11-2013. Estabelece exigências para cadastramento de viveiros, jardins clonais, plantas matrizes produtoras de sementes e normas técnicas de defesa sanitária vegetal, para a produção, comércio e o transporte de mudas, borbulhas e sementes de seringueira (hevea spp) no Estado de São Paulo. Disponível em $<$ http://www.defesaagropecuaria. sp.gov.br>. Acesso em: 26 jun. 2014

9. Santos, J.M. dos. Meloidogyne exigua e Botryodiplodia theobromae, principais componentes bióticos de uma doença complexa da seringueira em Mato Grosso. Fitopatologia Brasileira, Brasília, D.F. v. 28, p. 341, 1995.

10. Santos, J.M. dos et al. Meloidogyne exigua, sério patógeno da seringueira nas plantações. In: Michelin, em Rondonópolis, MT. In: CONGRESSO BRASILEIRO DE NEMATOLOGIA, 1992 Lavras, MG. Anais... Lavras: Sociedade Brasileira de Fitopatologia, 1992. v. 17, p.75.

11. Scallopi Junior. E. J. Seringueira: panorama, pesquisa e perspectiva de clones. Pesquisa \& Tecnologia, v. 8, n. 47, set. 2011. Disponível em < http:// www.aptaregional.sp.gov.br. Acesso em: 10 jun. 2012

12. Thankamony, S.; Kothandaraman, R.; Jacob, C. K.; Jose, V. T. Density and frequency of root-knot nematode, Meloidogyne incognita in rubber plantations. Proceedings Plantation Crops Symposium Placrosym XV, Mysore, India, 2002, p. 561-564. 